\title{
Two New Bisorbicillinoids Isolated from a Deep-sea Fungus, Phialocephala sp. FL30r
}

\author{
Dehai Li, Fengping Wang, Shengxin Cai, Xiang Zeng, Xiang Xiao, Qianqun Gu, \\ Weiming Zhu
}

Received: September 29, 2006 / Accepted: May 7, 2007

(C) Japan Antibiotics Research Association

\begin{abstract}
Two new bisorbicillinoids, named oxosorbiquinol (1) and dihydrooxosorbiquinol (2), were isolated from a deep-sea fungus, Phialocephala sp., and their structures established using spectroscopic methods. The absolute configurations of $\mathbf{1}$ and $\mathbf{2}$ were determined by their biosynthesis route and analysis of the $\mathrm{CD}$ spectrum. Their cytotoxic effects on P388, A-549, HL60, BEL7402 and K562 cell lines were examined by the MTT method.
\end{abstract}

Keywords bisorbicillinoids, deep-sea fungus, Phialocephala sp., cytotoxicity

\section{Introduction}

Sorbicillinoids, the related dimeric bisorbicillinoids, and other natural products have been found in a wide variety of fungal sources. Some of the bisorbicillinoids may be biosynthesized via an unusual type of Diels-Alder reaction and also show promising biological properties, such as antifungal, antitumor and antioxidant activities $[1,2]$.

During a program to discover and isolate novel bioactive natural products, over 300 strains of microorganisms derived from deep-sea samples have been screened against a K562 cell line. Among them, the fungal strain FL30r, identified as Phialocephala sp., showed cytotoxicity in vitro. The strain was isolated from a deep-sea sediment sample (depth $5059 \mathrm{~m}$ ) collected from ES304

Q. Gu, W. Zhu (Corresponding author), D. Li, S. Cai: Key Laboratory of Marine Drugs, Chinese Ministry of Education; Institute of Marine Drugs and Food, Ocean University of China, Qingdao 266003, PR China,

E-mail: weimingzhu@ouc.edu.cn,guqianq@ouc.edu.cn
(W145 $23^{\prime} 03^{\prime \prime}, \mathrm{N} 8^{\circ} 19^{\prime} 50^{\prime \prime}$ ) in 2003 . Studies of the active constituents of this fungus led to the isolation of two new bisorbicillinoids, named oxosorbiquinol (1) and dihydrooxosorbiquinol (2) (Fig. 1). In this paper we report their isolation, structure elucidation and cytotoxic activities.

\section{Materials and Methods}

\section{General}

Optical rotations were obtained on a JASCO P-1020 digital polarimeter. IR spectra were taken on a NICOLET NEXUS

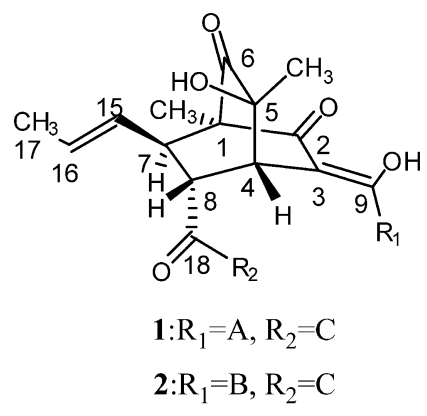

Sorbiquinol: $\mathrm{R}_{1}=\mathrm{A}, \mathrm{R}_{2}=\mathrm{D}$

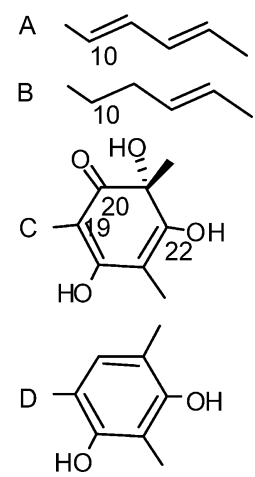

Fig. 1 Structures of oxosorbiquinol (1) and dihydrooxosorbiquinol (2).

F. Wang, X. Zeng, X. Xiao: Key Laboratory of Marine Biogenetic Resources, Third Institute of Oceanography, The State Oceanic Administration, Xiamen, PR China 
470 spectrophotometer in $\mathrm{KBr}$ discs. UV spectra were recorded on Beckman DU ${ }^{\circledR} 640$ spectrophotometer. ESIMS was measured on a Q-Tof Ultima GLOBAL mass spectrometer. ${ }^{1} \mathrm{H}-,{ }^{13} \mathrm{C}-\mathrm{NMR}$ and DEPT spectra and 2D-NMR were recorded on a JEOL JNM-ECP 600 spectrometer using TMS as internal standard. Semipreparative HPLC was performed using an ODS column (YMC-Pack ODS-A, $10 \times 250 \mathrm{~mm}, 5 \mu \mathrm{m}$ ).

\section{Fungus and Culture}

A small loop of spores growing on a PDA slant was inoculated into a $250-\mathrm{mL}$ Erlenmeyer flask containing $75 \mathrm{~mL}$ sea-water-based culture medium (glucose $2.0 \%$, potato extract $20 \%$, yeast extract $0.2 \%$, peptone $0.3 \%$, $\mathrm{NaCl} 1 \%, \mathrm{MgCl}_{2} \cdot 6 \mathrm{H}_{2} \mathrm{O} 0.08 \%, \mathrm{KCl} 0.1 \%$ ) and cultured at $28^{\circ} \mathrm{C}$ for 2 days on a rotary shaker at $120 \mathrm{rpm}$. Then, $10 \mathrm{~mL}$ of the resultant seed culture was inoculated into a $500-\mathrm{mL}$ Erlenmeyer flask containing $150 \mathrm{~mL}$ of the above culture medium and incubated (500 flasks) for 10 days under the same conditions.

\section{Isolation}

Seventy liters of whole broth was filtered through cheesecloth to separate the supernatant and mycelia. The former was extracted with ethyl acetate, while the latter was extracted with acetone. The acetone extraction was evaporated under reduced pressure to afford an aqueous solution and then extracted with ethyl acetate. The two ethyl acetate extracts were combined and concentrated in vacuo to give a crude extract $(50.0 \mathrm{~g})$. This was subjected to silica gel column chromatography eluted in gradient ratios with petroleum ether-chloroform and chloroformmethanol, respectively. And the active fragment (petroleum ether: chloroform 1:5) was further chromatographed on Sephadex LH-20 using chloroform:methanol 1:1 as elution, repeatedly. Further purification was carried about using HPLC on a ODS semi-preparative column (gradient eluted with $80 \sim 90 \%$ methanol/water containing TFA 3\%) to obtain $\mathbf{1}(6.5 \mathrm{mg})$ and $\mathbf{2}(1.6 \mathrm{mg})$.

\section{Physico-chemical Properties}

1: brown syrup; $[\alpha]_{\mathrm{D}}^{20}+255^{\circ}(c 0.10, \mathrm{MeOH})$; HRESI-MS $m / z 511.1950[\mathrm{M}-\mathrm{H}]^{-}$(calcd for $\mathrm{C}_{28} \mathrm{H}_{31} \mathrm{O}_{9}, 511.1968$ ); UV $\lambda_{\max }^{\mathrm{MeOH}} \mathrm{nm}(\log \varepsilon) 232(2.8), 341(4.0) ; \mathrm{CD}(\mathrm{MeOH}) \lambda_{\max } \mathrm{nm}$ $(\Delta \varepsilon) 366(+34.8), 310(-44.7), 249(+14.1), 229(+0.4)$, $205(+6.2)$; IR $v_{\max }(\mathrm{KBr}) \mathrm{cm}^{-1} 3421,2929,1730,1670$, 1631, 1605, 1560, 1454, 1382, 1247, 997.

2: brown syrup; $[\alpha]_{\mathrm{D}}^{20}+94^{\circ}(c 0.08, \mathrm{MeOH})$; HRESI-MS $m / z 537.2110[\mathrm{M}+\mathrm{Na}]^{+}$(calcd for $\mathrm{C}_{28} \mathrm{H}_{34} \mathrm{O}_{9} \mathrm{Na}, 537.2101$ ); $\mathrm{UV} \lambda_{\max }^{\mathrm{MeOH}} \mathrm{nm}(\log \varepsilon) 232$ (2.5), 279 (3.7); CD (MeOH) $\lambda_{\max } \mathrm{nm}(\Delta \varepsilon) 328(+59.5), 288(-74.3), 249(+15.1), 239$
$(+8.1), 221(+23.5) ;$ IR $v_{\max }(\mathrm{KBr}) \mathrm{cm}^{-1} 3419,2936$, 1728, 1639, 1631, 1601, 1537, 1449, 1247, 968.

\section{Biological Assay}

Cytotoxic activity was evaluated by the MTT $[2,3]$ method. The $\mathrm{IC}_{50}$ values were obtained using the Bliss method.

\section{Results and Discussion}

\section{Structure Determination}

1: Its molecular formula, $\mathrm{C}_{28} \mathrm{H}_{32} \mathrm{O}_{9}$, was established by HRESI-MS, which was in agreement with its ${ }^{1} \mathrm{H}$ - and ${ }^{13} \mathrm{C}$ NMR data. The IR absorptions at 3421, 1670, 1631, 1605 and $1560 \mathrm{~cm}^{-1}$ were suggestive of the presence of hydroxy, $\alpha, \beta$-unsaturated carbonyl and two enolized diketones [4], which were proved by the very low field chemical shifts of two hydroxys ( $\delta: 18.50$ and 14.00) in the ${ }^{1} \mathrm{H}-\mathrm{NMR}$ spectrum. The ${ }^{1} \mathrm{H}-\mathrm{NMR}$ spectrum displayed the presence of a sorbyl group $[4,5][5.81(1 \mathrm{H}, \mathrm{d}, 14.8 \mathrm{~Hz}), 7.22(1 \mathrm{H}, \mathrm{dd}$, $14.8,10.3 \mathrm{~Hz}), 6.08(1 \mathrm{H}, \mathrm{m}), 6.14(1 \mathrm{H}, \mathrm{m})$ and $1.85(3 \mathrm{H}, \mathrm{d}$, $6.4 \mathrm{~Hz})]$ and a substituted dihydrosorbyl group $[1,6][3.19$ $(1 \mathrm{H}, \mathrm{dd}, 10.3,5.8 \mathrm{~Hz}), 4.37(1 \mathrm{H}, \mathrm{d}, 3.8 \mathrm{~Hz}), 5.04(1 \mathrm{H}, \mathrm{dd}$, $14.8,11.6 \mathrm{~Hz}), 5.41(1 \mathrm{H}, \mathrm{m})$ and $1.60(3 \mathrm{H}, \mathrm{d}, 4.5 \mathrm{~Hz})]$, which were also confirmed by the ${ }^{1} \mathrm{H}-{ }^{1} \mathrm{H}$ COSY and HMBC spectra. The $E$ configuration of the two double bonds in the sorbyl residue and the double bond in the dihydrosorbyl chain was determined via the large coupling constants observed, and further confirmed by the observed correlation between $\mathrm{H}-10$ and $\mathrm{H}-12, \mathrm{H}-11$ with $\mathrm{H}-13$, and $\mathrm{H}-17$ and $\mathrm{H}-15$ in the NOESY spectrum, respectively.

The ${ }^{13} \mathrm{C}$-NMR spectrum of $\mathbf{1}$ showed 28 carbons. Careful analysis and comparison of the ${ }^{13} \mathrm{C}-\mathrm{NMR}$ data and DEPT spectrum with sorbiquinol [6] revealed that 1 should have the same skeleton as that of sorbiquinol, except for the C20 carbonyl (195.9) instead of an $s p^{2}$ methine (129.0) and C-21 as $s p^{3}$ carbon (75.8) instead of $s p^{2}$ carbon (115.0), which was verified by the $\mathrm{HMBC}$ correlatons between $\mathrm{CH}_{3}-$ 21 and C-20, C-21, and C-22 (Table 1).

The $\mathrm{H}-4$ and $\mathrm{CH}_{3}-1$ were located on the equatorial bond of the bicyclo [2, 2, 2] moiety which in the boat form [7]. In the NOESY spectrum (Fig. 2), the cross peaks observed between $\mathrm{H}-7$ with $\mathrm{CH}_{3}-1$ indicated that they were in cis arrangement. The coupling constant between $\mathrm{H}-7$ and $\mathrm{H}-8$ $\left(J_{7,8}=5.8 \mathrm{~Hz}\right.$ ) implied that $\mathrm{H}-8$ was trans to $\mathrm{H}-7$ (the coupling constant over $10 \mathrm{~Hz}$ in the cis form) [7]. The cross peaks of $\mathrm{H}-8$ with $\mathrm{H}-15$ established that the 1-propenyl group was cis to H-8.

The absolute stereochemistry of $\mathbf{1}$ was determined from the biosythesis route and analysis of the CD spectrum. Recent research has shown that known sobicillin dimeric 
Table $1{ }^{1} \mathrm{H}$ and ${ }^{13} \mathrm{C}$ NMR data for oxosorbiquinol (1) and dihydrooxosorbiquinol (2) (CDCl 3,600 and $150 \mathrm{MHz}, \mathrm{TMS}, \delta$ ppm)

\begin{tabular}{|c|c|c|c|c|c|c|}
\hline \multirow{2}{*}{ NO } & \multicolumn{3}{|c|}{1} & \multicolumn{3}{|c|}{2} \\
\hline & $\delta_{\mathrm{C}}$ & $\delta_{\mathrm{H}}(\mathrm{J}$ in $\mathrm{Hz})$ & $\mathrm{HMBC}(\mathrm{H} \rightarrow \mathrm{C})$ & $\delta_{\mathrm{C}}$ & $\delta_{\mathrm{H}}(\mathrm{J}$ in $\mathrm{Hz})$ & $\mathrm{HMBC}(\mathrm{H} \rightarrow \mathrm{C})$ \\
\hline 1 & 63.3 & & & 62.7 & & \\
\hline 2 & 198.1 & & & 197.0 & & \\
\hline 3 & 107.1 & & & 106.9 & & \\
\hline 4 & 45.3 & $3.48(1 \mathrm{H}$, br.s $)$ & $2,3,5,6,7$ & 45.8 & $3.43(1 \mathrm{H}$, br.s $)$ & $2,3,5,6,7,9$ \\
\hline 5 & 75.5 & & & 75.5 & & \\
\hline 6 & 210.6 & & & 214.1 & & \\
\hline 7 & 47.2 & $3.19(1 \mathrm{H}, \mathrm{dd}, 10.35 .8)$ & $6,8,15$ & 47.4 & $3.15(1 \mathrm{H}, \mathrm{dd}, 10.85 .9)$ & 6 \\
\hline 8 & 48.0 & $4.37(1 \mathrm{H}, \mathrm{br} . \mathrm{d}, 3.8)$ & 7,18 & 47.8 & $4.32(1 \mathrm{H}, \mathrm{d}, 3.2)$ & 3 \\
\hline 9 & 168.6 & & & 180.0 & & \\
\hline 10 & 117.2 & $5.81(1 \mathrm{H}, \mathrm{d}, 14.8)$ & 12 & 31.8 & $2.02(1 \mathrm{H}, \mathrm{m}) ; 2.24(1 \mathrm{H}, \mathrm{m})$ & 9 \\
\hline 11 & 142.4 & $7.22(1 \mathrm{H}, \mathrm{dd}, 14.8$ 10.3) & 9,13 & 29.0 & $2.15(2 \mathrm{H}, \mathrm{m})$ & 9 \\
\hline 12 & 130.7 & $6.08(1 \mathrm{H}, \mathrm{m})$ & 11 & 126.6 & $5.26(1 \mathrm{H}, \mathrm{m})$ & 14 \\
\hline 13 & 140.0 & $6.14(1 \mathrm{H}, \mathrm{m})$ & 14 & 128.8 & $5.35(1 \mathrm{H}, \mathrm{m})$ & 14 \\
\hline 14 & 18.8 & $1.85(3 \mathrm{H}, \mathrm{d}, 6.4)$ & 12,13 & 17.8 & $1.58(3 \mathrm{H}, \mathrm{d}, 6.6)$ & 12,13 \\
\hline 15 & 128.6 & $5.04(1 \mathrm{H}, \mathrm{dd}, 14.8$ 11.6) & & 128.4 & $5.02(1 \mathrm{H}, \mathrm{dd}, 14.8,10.8)$ & 16 \\
\hline 16 & 130.1 & $5.41(1 \mathrm{H}, \mathrm{m})$ & 17 & 130.1 & $5.26(1 \mathrm{H}, \mathrm{m})$ & 17 \\
\hline 17 & 17.8 & $1.60(3 \mathrm{H}, \mathrm{d}, 4.5)$ & 16 & 17.7 & $1.59(3 \mathrm{H}, \mathrm{d}, 6.0)$ & 15,16 \\
\hline 18 & 200.5 & & & 200.5 & & \\
\hline 19 & 103.8 & & & 99.9 & & \\
\hline 20 & 195.9 & & & 196.0 & & \\
\hline 21 & 75.8 & & & 76.3 & & \\
\hline 22 & 170.1 & & & 170.3 & & \\
\hline 23 & 104.4 & & & 104.3 & & \\
\hline 24 & 190.0 & & & 190.8 & & \\
\hline $\mathrm{CH}_{3}-1$ & 10.1 & $1.15(3 \mathrm{H}, \mathrm{s})$ & $1,2,6,7$ & 10.0 & $1.14(3 \mathrm{H}, \mathrm{s})$ & $1,2,6,7$ \\
\hline $\mathrm{CH}_{3}-5$ & 24.4 & $1.26(3 \mathrm{H}, \mathrm{s})$ & $4,5,6$ & 24.6 & $1.28(3 \mathrm{H}, \mathrm{s})$ & $4,5,6$ \\
\hline $\mathrm{CH}_{3}-21$ & 30.5 & $1.60(3 \mathrm{H}, \mathrm{s})$ & $20,21,22$ & 30.7 & $1.58(3 \mathrm{H}, \mathrm{s})$ & $20,21,22$ \\
\hline $\mathrm{CH}_{3}-23$ & 6.9 & $1.82(3 \mathrm{H}, \mathrm{s})$ & $22,23,24$ & 6.9 & $1.86(3 \mathrm{H}, \mathrm{s})$ & $22,23,24$ \\
\hline $\mathrm{OH}-24$ & & $18.5(1 \mathrm{H}, \mathrm{s})$ & $18,19,23,24$ & & $18.8(1 \mathrm{H}, \mathrm{s})$ & \\
\hline $\mathrm{OH}-9$ & & $14.0(1 \mathrm{H}, \mathrm{s})$ & $3,9,10$ & & $14.5(1 \mathrm{H}, \mathrm{s})$ & $3,9,10$ \\
\hline
\end{tabular}

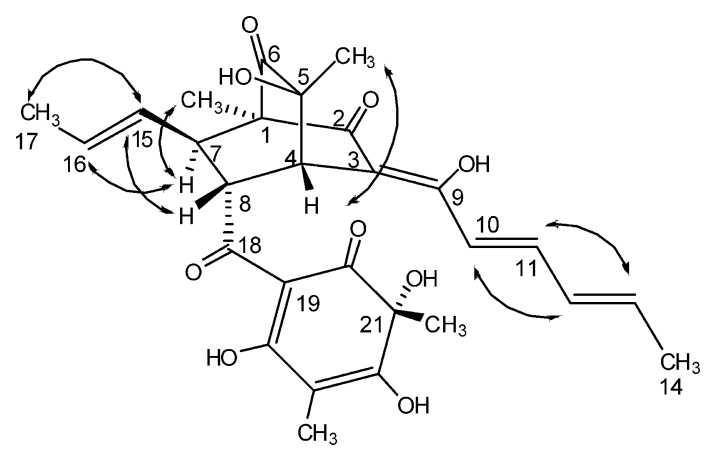

Fig. 2 NOESY correlations for $\mathbf{1}$. compounds, such as bisvertinolone and bisorbibutenolide that were isolated from this strain, were biosynthesized from two molecules of sorbicillinol or oxosorbicillinol by [4+2] cycloadditions or Michael addition ketalization sequences. The configuration at C-6 of sorbicillinol or oxosorbicillinol did not change in the two reactions, so it was also suggested that $\mathbf{1}$ was likely biosynthesized from sorbicillinol and oxosorbicillinol by $[4+2]$ cycloadditions that are similar to what was proposed for sorbiquinol [6]. The CD spectrum of $\mathbf{1}$ also showed strong splitting Cotton effect at $366 \mathrm{~nm}(\Delta \varepsilon+34.8)$ and $310 \mathrm{~nm}(-44.7)$. Therefore, the configurations at C-5 and C-21 of 1 should be respectively similar to sorbicillinol and oxosorbicillinol [8] and may have the $(S)$ and $(R)$ configurations, from the point of biogenesis as shown in Fig. 1. 
Table 2 The activities of compounds $\mathbf{1}$ and $\mathbf{2}$ on cancer cell lines

\begin{tabular}{|c|c|c|c|c|c|}
\hline \multirow{2}{*}{ Compound } & \multicolumn{5}{|c|}{$\mathrm{IC}_{50}(\mu \mathrm{M})$} \\
\hline & P388 & A549 & HL60 & BEL7402 & K562 \\
\hline 1 & 29.9 & 103.5 & 8.9 & 12.7 & 56.3 \\
\hline 2 & 40.3 & 97.6 & 10.5 & 31.8 & 68.2 \\
\hline
\end{tabular}

2: Its molecular formula was determined to be $\mathrm{C}_{28} \mathrm{H}_{34} \mathrm{O}_{9}$ by HRESI-MS, which was well consistent with its ${ }^{1} \mathrm{H}$ - and ${ }^{13} \mathrm{C}-\mathrm{NMR}$ data. The IR spectrum of $\mathbf{2}$ showed absorptions at $3419,1728,1639,1631,1601,1537$, which was very similar to 1 . Detailed analysis and comparison of the ${ }^{1} \mathrm{H}-$ and ${ }^{13} \mathrm{C}$-NMR data with those of $\mathbf{1}$ revealed that $\mathbf{2}$ possesses the same planar structure as $\mathbf{1}$, except that the sorbyl group in $\mathbf{1}$ corresponds to a dihydrosorbyl group in $\mathbf{2}$. The conclusion was validated by the HMBC experiments (Table 1). The CD cotton effect $[\Delta \varepsilon 328(+59.5), 288(-74.3)$, $249(+15.1), 239(+8.1), 221(+23.5)]$ revealed the absolute stereochemistry of $\mathbf{2}$ is the same as that of $\mathbf{1}$.

\section{Cytotoxic Activities}

The cytotoxic effects of $\mathbf{1}$ and $\mathbf{2}$ were preliminarily evaluated in P388, A-549, HL60, BEL7402 and K562 cell lines, as shown in Table 2.

$\mathbf{1}$ and $\mathbf{2}$ showed weak cytotoxic activities against the five cell lines, except for the A549 cell line.

Most of the bisorbicillinoids were Diels-Alder adductions which occurred between the hexacyclic ring of two sorbicill derivers $[1,2,4 \sim 7]$. The adduction between the hexacyclic ring and sorbyl side chain was unusual in nature, and only one bisorbicillinoid, sorbiquinol [6], has hitherto been found. $\mathbf{1}$ and $\mathbf{2}$, as new members of this kind of bisorbicillinoids, therefore hold promise as potential anticancer agents. Detailed studies on their antitumor activities and related mechanisms of action are being undertaken.

Acknowledgement This work was founded by the Chinese Ocean Mineral Resource R\&D Association (DY105-2-04) and an international cooperation between Australia and China (2005 DFA 30030-4). The anti-tumor activity was determined by the Shanghai Institute of Materia Medica, Chinese Academy of
Sciences.

\section{References}

1. Bringmanna $G$, Lang $G$, Gulder TAM, Tsuruta $H$, Muhlbacher J, Maksimenka K, Steffens S, Schaumann K, Stohr R, Wiese J, Imhoff JF, Perovic-Ottstadt S, Boreiko $\mathrm{O}$, Muller WEG. The first sorbicillinoid alkaloids, the antileukemic sorbicillactones A and B, from a spongederived Penicillium chrysogenum strain. Tetrahedron 61: 7252-7265 (2005)

2. Liu WZ, Gu QQ, Zhu WM, Cui CB, Fan GT. Two new benzoquinone derivatives and two new bisorbicillinoids were isolated from a marine-derived fungus Penicillium terrestre. J Antibiot 58: 441-446 (2005)

3. Mossman T. Rapid colorimetric assay for cellular growth and survival: application to proliferation and cytotoxicity assays. J Immunol Meth 65: 55-63 (1983)

4. Andrade R, Ayer WA, Mebe PP. The metabolites of Trichoderma longibrachiatum. Part I. Isolation of the metabolites and the structure of trichodimerol. Can J Chem 70: 2526-2535 (1992)

5. Andrade R, Ayer WA, Trifonov LS. The metabolites of Trichoderma longibrachiatum. III. Two new tetronic acids: 5-hydroxyvertinolide and bislongiquinolide. Aust J Chem 50: 255-258 (1997)

6. Andrade R, Ayer WA, Trifonov LS. The metabolites of Trichoderma longivrachiatum. Part II. The structures of trichodermolide and sorbiquinol. Can J Chem 74: 371-379 (1996)

7. Zhao TZ. ${ }^{1}$ H-NMR; Beijing University Press: Beijing, 1983 , Vol. 1, pp. 96-99.

8. Abe N, Yamamoto K, Hirota A. Novel fungal metabolites, demethylsorbicillin and oxosorbicillinol, isolated from Trichoderma sp. USP-2690. Biosci Biotechol Biochem 64(3): 620-622 (2000) 